\title{
Kinetic Study of the Heterogeneous Catalytic Esterification of Acetic Acid with Methanol Using Amberlyst ${ }^{\circledR 15}$
}

\author{
S. Lux, "T. Winkler, G. Berger, and M. Siebenhofer \\ Graz University of Technology, Institute of Chemical Engineering \\ and Environmental Technology, NAWI Graz \\ Inffeldgasse 25C, $8010 \mathrm{Graz}$, Austria
}

doi: 10.15255/CABEQ.2014.2083

Original scientific paper

Received: July 17, 2014

Accepted: November 22, 2015

\begin{abstract}
The synthesis of methyl acetate via esterification of acetic acid with methanol is a prominent example of equilibrium-limited esterification reactions with low reaction rates in the absence of catalysts. The acidic ion-exchange resin Amberlyst ${ }^{\circledR} 15$ is a potential heterogeneous catalyst. The aim of this study was to investigate the reaction kinetics of the heterogeneous catalytic esterification of acetic acid and methanol with Amberlyst ${ }^{\mathbb{B}} 15$, including the adsorption behaviour and heats of adsorption of the reactants on the ion-exchange resin. The reaction kinetics was modelled based on the Langmuir-Hinshelwood-Hougen-Watson approach. Independent adsorption experiments with non-reactive binary mixtures were performed and incorporated into the kinetic model. The heats of adsorption of the reactants were determined in order to account for the temperature dependency of the heterogeneous catalytic reaction. From the enthalpy of adsorption, physical interaction of all constituents with the catalyst was concluded. The Langmuir-Hinshelwood-Hougen-Watson model showed good agreement with the experimental results.
\end{abstract}

Key words:

esterification, heterogeneous catalysis, ion-exchange resin, methyl acetate

\section{Introduction}

The bulk chemicals esters contribute to commodity chemicals in nearly unlimited variety. Common fields of application include their use as solvents, plasticizers, surfactants, flavours, intermediates in preparative organic chemistry, and many more. ${ }^{1}$ Though well investigated, the technology of ester production offers some challenging characteristics regarding catalysis, operation conditions and downstream processing.

The synthesis of methyl acetate (MeOAc) via liquid-phase esterification of acetic acid (HOAc) and methanol $(\mathrm{MeOH})$ is a prominent example thereof. The reaction proceeds via the following reaction equation:

$$
\mathrm{CH}_{3} \mathrm{COOH}+\mathrm{CH}_{3} \mathrm{OH} \stackrel{\mathrm{H}^{+}}{\rightleftharpoons} \mathrm{CH}_{3} \mathrm{COOCH}_{3}+\mathrm{H}_{2} \mathrm{O}
$$

As a volatile solvent, methyl acetate is used for the production of coatings, nitro-cellulose, cellulose acetate, cellulose ethers and celluloid, as well as for a variety of resins, plasticizers, lacquers and certain fats. ${ }^{2}$ Besides the synthesis of methyl acetate, this esterification reaction may potentially be applied in the recovery of dilute acetic acid from aqueous solutions. $^{3,4}$

"Corresponding author: Susanne Lux: susanne.lux@tugraz.at
However, the production of high-purity methyl acetate is challenging due to its reaction kinetics and difficulties in product isolation. It is a typical example of an equilibrium-limited reaction in which the conversion is low due to the limits imposed by the thermodynamic equilibrium. Furthermore, intramolecular catalysis by acetic acid is slow as it is considered a weak acid with a $\mathrm{p} K_{\mathrm{a}}$ of $4.77 .{ }^{5}$ Without a catalyst, the equilibrium is not reached within 49 days at 313 K. ${ }^{6}$ Additionally, methyl acetate forms low-boiling binary azeotropes with both the educt methanol $\left(x_{\mathrm{MeOAc}}=0.65, T_{\mathrm{bp}}=326.7 \mathrm{~K}\right)^{7}$ and the by-product water $\left(\mathrm{H}_{2} \mathrm{O}\right)\left(x_{\mathrm{MeOAc}}=0.90, T_{\mathrm{bp}}=\right.$ $329.1 \mathrm{~K})^{8}$.

The use of acidic ion-exchange resins as catalysts for esterification reactions is well documented in the literature. ${ }^{2,9-11}$ For modelling of the reaction kinetics, different approaches have been described, including the ideal pseudo-homogeneous, the non-ideal pseudo-homogeneous, and the adsorption-based Eley-Rideal and the Langmuir-Hinshelwood-Hougen-Watson (LHHW) model. ${ }^{11}$ Due to their differences in polarity, the reactants show different adsorption behaviour on the ion-exchange resins. Interactions of the solid ion-exchange resin and the liquid reactants significantly affect the reaction kinetics and have to be taken into account. Pöpken et al. ${ }^{9}$ investigated the reaction kinetics and the chemical equilibrium of the esterification of 
acetic acid with methanol catalysed by the ion-exchange resin Amberlyst ${ }^{\mathbb{}} 15$. They performed independent adsorption experiments with non-reactive binary mixtures to determine the adsorption equilibrium constants, and incorporated them into the kinetic expression. The Langmuir isotherms applied by Pöpken et al. ${ }^{9}$ were based on the assumption that, for each component, the adsorbed mass on the catalyst is constant. This model showed significant improvement to any pseudo-homogeneous model with respect to the agreement of kinetics and thermodynamics. So far, the heats of adsorption of the reactants on the ion-exchange resin have been neglected when modelling the temperature dependency of the reaction kinetics. Therefore, the aim of this work was both to check the reaction kinetics of the heterogeneous catalytic esterification of acetic acid and methanol with ion-exchange resins, and to investigate the adsorption behaviour and heats of adsorption of the reactants on the ion-exchange resin. For comparison with the data given in literature, Amberlyst ${ }^{\mathbb{}} 15$ was used as catalyst. Modelling of the experimental kinetic data was based on the original LHHW concept, but extended with the heats of adsorption. In extension to Pöpken et al. ${ }^{9}$, the Langmuir isotherms in this paper were based on the assumption of constant total amount of adsorbed molecules from the multi-component mixtures. This was already proposed by Song et al. ${ }^{10}$ who also assumed uniform molecular area of each reactant on the ion-exchange resin. The non-idealities of the liquid phase were taken into account by applying the NRTL-model.

Song et al. ${ }^{10}$ defined expressions for the adsorption constants of all components that were directly related to the adsorption constant of methyl acetate. The latter and the forward reaction rate were determined simultaneously by fitting the kinetic data. As the independency of the adsorption experiments was not ensured, the extrapolation capabilities of the kinetic model were significantly reduced. ${ }^{9}$

Adsorption constants and rate constants were derived independently in this study. Furthermore, the effect of the amount of catalyst, particle size of the catalyst, speed of the stirrer, reaction temperature, and initial molar ratio of the reactants were investigated.

\section{Materials and methods}

\section{Materials}

Reagent grade methanol ( $\geq 99.9 \%$, Roth), acetic acid ( $\geq 99.8 \%$, Baker) and methyl acetate ( $\geq 99 \%$, Merck) were used without further purification. Deionised water was used in the experiments.
For titrimetric analysis of the concentration of acidic sites of the ion-exchange resin, $0.1 \mathrm{~mol} \mathrm{dm}^{-3}$ $\mathrm{KOH}$ (Roti ${ }^{\circledR}$ Volum, Roth) was used.

The ion-exchange resin Amberlyst ${ }^{\circledR} 15$ (wet) was provided by Sigma Aldrich in its hydrogen form with average moisture content of $48 \mathrm{wt} \%$. This macroreticular resin consists of a styrene-divinylbenzene matrix and sulfonic acid substituents as catalytic sites. The concentration of acidic sites was $4.7 \mathrm{eq}^{+} \mathrm{g}^{-1}$ of dry resin, which was determined by titration with $\mathrm{KOH}$. This value agreed well with the value given by the manufacturer. According to the supplier, the surface area of the resin was $53 \mathrm{~m}^{2} \mathrm{~g}^{-1}$, the average pore diameter was $30 \mathrm{~nm}$, and the total pore volume was $0.4 \mathrm{~cm}^{3} \mathrm{~g}^{-1}$. Maximum operation temperature of the resin is $393 \mathrm{~K}$. The median value $x_{50}$ of the particle size distribution of the resin beads was determined as $698.53 \mu \mathrm{m} \pm 17.30 \mu \mathrm{m}$ with a QICPIC particle analyser (Sympatec $\mathrm{GmbH}$ ) equipped with a RODOS injection disperser.

Before usage, Amberlyst ${ }^{\circledR} 15$ was washed with methanol and deionised water in a temperature-controlled mixing flask at $318 \mathrm{~K}$ until the supernatant liquid remained colourless. It was dried in a vacuum drier at $363 \mathrm{~K}$ for $24 \mathrm{~h}$ and stored in an exsiccator until used for the adsorption and kinetics experiments. Residual moisture of the ion-exchange resin was below $5 \mathrm{wt} \%$. Drying at temperatures above $393 \mathrm{~K}$ has to be avoided since it results in the loss of catalytic sites due to desulfonisation.

For investigation of possible internal mass-transfer resistance, Amberlyst ${ }^{\circledR} 15$ was fractionated into three particle size ranges. Before fractionation, Amberlyst ${ }^{\mathbb{B}} 15$, which was washed and dried, was kept at atmospheric conditions for equilibration with atmospheric moisture. The equilibrium water content was $25 \mathrm{wt} \%$. This was regarded as the reference state for particle size determination. Fractionation was carried out in a Fritsch Analysette sieve tray with $250 \mu \mathrm{m}, 500 \mu \mathrm{m}$ and $800 \mu \mathrm{m}$ mesh widths.

\section{Adsorption experiments}

Adsorption experiments were performed for the non-reactive binary mixtures $\mathrm{HOAc}-\mathrm{H}_{2} \mathrm{O}$, $\mathrm{MeOH}-\mathrm{H}_{2} \mathrm{O}$, and $\mathrm{MeOAc}-\mathrm{MeOH}$. The non-reactive binary MeOAc-HOAc mixture was not taken into account. In the absence of polar components, acetic acid dimerises due to the formation of hydrogen bonds. Acetic acid dimers feature lower polarity than monomeric acetic acid and consequently show different adsorption behaviour. The presence of the polar components water and methanol is guaranteed in the reaction mixture at any time. 
Therefore, dimerisation of acetic acid can be neglected.

The experiments were carried out in a $500 \mathrm{~cm}^{3}$ 4-neck glass flask equipped with a reflux condenser and a plate-type agitator. The operating temperature in the flask was controlled and kept constant $( \pm 1 \mathrm{~K})$ with a heating plate (Heidolph MR Hei-Standard) connected to a Radlyes heat-on block and a Pt-100 temperature controller (Heidolph EKT 3001).

The experimental procedure of the adsorption experiments was based on the work of Song et al. ${ }^{10}$ The adsorption experiments were started by mixing $150 \mathrm{~g}$ of the pre-prepared non-reactive binary mixture and $55 \mathrm{~g}$ of dry ion-exchange resin. The initial mole fraction of the component with the higher relative polarity was 0.1 . Speed of agitation was $50 \mathrm{rpm}$. The mixture was heated to $313 \mathrm{~K}$, and agitated for 30 minutes to guarantee equilibration. A sample was then taken for the first data point. In preliminary experiments it was proven that equilibration was already achieved within 2-3 minutes. Sampling was accomplished via the fourth neck of the glass flask, which was equipped with a septum. With a syringe, $0.5 \mathrm{~cm}^{3}$ samples were taken, cooled in ice water, and analysed. The next data point was obtained by admixing the more polar component to the initial mixture and repeating the same procedure. When the volume of the liquid exceeded $400 \mathrm{~cm}^{3}$, the experiment was stopped in order to prevent accumulation of errors due to hindered mixing and low ion-exchange resin/liquid phase ratio. In the next run, a liquid phase composition close to the last one was used and the procedure repeated. Thus, the entire range of binary non-reactive compositions was studied in steps of $10 \%$.

For determination of the heat of adsorption of reactants on the ion-exchange resin, a $500 \mathrm{~cm}^{3}$ Dewar vessel was used. The sealed vessel was equipped with a plate-type agitator and a Pt-100 resistor-type thermometer (Lauda DigiCal DCM2, accuracy $\pm 0.03 \mathrm{~K}$ ). The experiments were started by mixing $80 \mathrm{~g}$ of dry ion-exchange resin and $400 \mathrm{~g}$ of the undiluted liquid substance at ambient temperature. The temperature change was recorded until the temperature in the Dewar vessel remained constant. This was generally achieved after 90 minutes. Agitator speed was $250 \mathrm{rpm}$. It was proven first that the temperature change via application of energy through agitation could be neglected due to the low viscosity of the substances. Mass and specific heat capacity of both the liquid mixture and the solid ion-exchange resin were used to determine the heat of adsorption. The specific heat capacity of polystyrene $\left(1.3 \mathrm{~kJ} \mathrm{~kg}^{-1} \mathrm{~K}^{-1}\right)^{12}$ was used for Amberlyst ${ }^{\circledR} 15$.
Prior to adsorption experiments, the heat capacity of the Dewar vessel was calibrated with water.

\section{Kinetics experiments}

For investigation of reaction kinetics, the same experimental setup was used as for the adsorption experiments. Feed mixtures of methanol and acetic acid were placed in the reactor and heated to the desired reaction temperature. Preliminary tests proved that esterification of acetic acid and methanol can be neglected during this start-up phase. The dry ion-exchange resin was pre-swollen in acetic acid and added to the feed mixture to start the reaction. Liquid samples were taken in specified time intervals starting with a 2-minute interval at the beginning, quenched in ice water, and analysed. Sample volume was less than $1 \mathrm{~cm}^{3}$.

The effect of stirrer speed was investigated in a range of $40-150 \mathrm{rpm}$. The mass of catalyst was varied from $10 \mathrm{~g}$ to $30 \mathrm{~g}$ in $300 \mathrm{~g}$ liquid reaction mixture. The effect of particle size of the ion-exchange resin was studied for $250-500 \mu \mathrm{m}, 500-800 \mu \mathrm{m}$, and $>800 \mu \mathrm{m}$ fractions. The reaction temperature was varied between $308 \mathrm{~K}$ and $323 \mathrm{~K}$, and the molar feed ratio of methanol to acetic acid was varied from $4: 1$ to $1: 4$.

\section{Sample analysis}

The liquid samples were analysed by gas chromatography (Shimadzu GC-2010 Plus). In order to suppress further reaction in the sample vials due to intramolecular catalysis of acetic acid, the temperature of the sample compartment was kept at $278 \mathrm{~K}$ with a Lauda Ecoline RE 104 cryostat. The AOC20i Auto Injector worked in split mode with a split ratio of 30:1. Substances were separated in a SUPEL-QTMPlot fused-silica capillary column $(30 \mathrm{~m} \times 0.53 \mathrm{~mm} \times 30 \mu \mathrm{m})$, and quantified by a thermal conductivity detector (TCD) and a flame ionization detector (FID). The TCD was operated on Helium carrier gas (21.3 $\mathrm{kPa}$ inlet pressure) at $553 \mathrm{~K}$. The FID was operated at $523 \mathrm{~K}$. The temperature programme in the column oven was $313 \mathrm{~K}$ ( $2 \mathrm{~min})-15 \mathrm{~K} \mathrm{~min}^{-1}-423 \mathrm{~K}(6 \mathrm{~min})$. The total time of each run was 15 minutes.

\section{Theory \\ NRTL-Model}

The non-ideal behaviour of the liquid phase was considered by activities $a_{\mathrm{i}}$. Activity coefficients $\gamma_{i}$ were derived from the NRTL-model (Equations (1), (2) and (3)). 


$$
\begin{gathered}
\ln \gamma_{i}=\frac{\sum_{j} \tau_{j i} G_{j i} x_{j}}{\sum_{k} G_{k i} x_{k}}+ \\
+\sum_{j} \frac{x_{j} G_{i j}}{\sum_{k} G_{k j} x_{k}}\left(\tau_{i j}-\frac{\sum_{n} x_{n} \tau_{n j} G_{n j}}{\sum_{k} G_{k j} x_{k}}\right) \\
\tau_{j i}=\frac{\left(g_{j i}-g_{i i}\right)}{R T} \\
G_{i j}=\exp \left(-\alpha_{i j} \tau_{i j}\right)
\end{gathered}
$$

NRTL-parameters for acetic acid, methanol, methyl acetate and water are listed in Table 1.

Table 1 - NRTL-parameters for acetic acid (1), methanol (2), methyl acetate (3), and water (4) at 1.013 bar and $314 K\left(t_{i i}=t_{i j}=0\right) .7,8,16$

\begin{tabular}{llllllll}
\hline$\tau_{12}$ & -0.348 & $\tau_{21}$ & 0.027 & $\tau_{31}$ & 2.374 & $\tau_{41}$ & 2.258 \\
$\tau_{13}$ & -0.932 & $\tau_{23}$ & 0.886 & $\tau_{32}$ & 0.280 & $\tau_{42}$ & 1.088 \\
$\tau_{14}$ & -0.637 & $\tau_{24}$ & -0.182 & $\tau_{34}$ & 1.434 & $\tau_{43}$ & 2.715 \\
$\alpha_{21}$ & 0.3051 & $\alpha_{24}$ & 0.2989 & $\alpha_{31}$ & 0.2969 & $\alpha_{32}$ & 0.2974 \\
$\alpha_{34}$ & 0.4056 & $\alpha_{41}$ & 0.2923 & & & & \\
\hline
\end{tabular}

\section{Development of the kinetic model}

Modelling of the reaction kinetics was based on the Langmuir-Hinshelwood-Hougen-Watson model. The Langmuir-Hinshelwood mechanism is based on a reaction mechanism in which two molecules are adsorbed on adjacent sites on the surface of the catalyst, with the surface reaction being the rate-controlling step. Consequently, the rate of reaction depends on the amount of adsorbed species.

For a non-reactive binary adsorption system of component 1 and component 2 in liquid phase, Kipling ${ }^{13}$ reported the overall mass balance as according to Equation 4.

$$
\frac{n_{0} \cdot \Delta x_{1}}{m_{\mathrm{cat}}}=n_{1}^{\mathrm{S}} \cdot x_{2,1}-n_{2}^{\mathrm{s}} \cdot x_{1,1}
$$

in which $n_{0}$ is the total initial number of moles in the liquid phase, $\Delta x_{1}$ is the change in the liquid phase mole fraction due to adsorption on the solid catalyst, $m_{\text {cat }}$ refers to the mass of catalyst, $n_{1} \mathrm{~S}$ and $n_{2}{ }^{\mathrm{S}}$ are the numbers of moles of component 1 and component 2, respectively, which are transferred to the catalyst per unit mass, and $x_{1,1}$ and $x_{2,1}$ are the mole fractions of components 1 and 2 in the liquid phase. The only unknowns which are not easily assessable through direct measurement are $n_{1}^{\mathrm{S}}$ and $n_{2} \mathrm{~S}$. Therefore, the amount of adsorbed species has to be approximated. Langmuir isotherms, mainly applied for modelling adsorption from gas phase, were already successfully applied for the adsorption from liquid phase. ${ }^{9,14}$ Markham and Benton ${ }^{15}$ first extended the application of Langmuir isotherms to multi-component mixtures. Further insertion of activities $a_{\text {; }}$, which account for the non-idealities in the liquid phase (Equation 5), results in the fractional load $x_{\mathrm{i}}^{\mathrm{S}}$ according to Equation 6

$$
\begin{gathered}
a_{i}=x_{i, 1} \cdot \gamma_{i} \\
x_{i}^{\mathrm{S}}=\frac{n_{i}^{\mathrm{S}}}{n^{\mathrm{S}}}=\frac{a_{i} K_{i}}{1+\sum_{j} a_{j} K_{j}}
\end{gathered}
$$

with $n^{\mathrm{S}}$ representing the maximum loading capacity of all adsorption sites. It is assumed that this value is constant for all species. Substitution of $n_{\mathrm{i}}^{\mathrm{S}}$ in Equation 4 through Equation 6 gives the following mass balance

$$
\begin{gathered}
\frac{n_{0} \cdot \Delta x_{1}}{m_{\text {cat }}}= \\
=n\left(\frac{a_{1} K_{1}}{1+a_{1} K_{1}+a_{2} K_{2}} x_{2,1}-\frac{a_{2} K_{2}}{1+a_{1} K_{1}+a_{2} K_{2}} x_{1,1}\right)
\end{gathered}
$$

which allows for the determination of the adsorptions equilibrium constants $K_{\mathrm{i}}$ from adsorption experiments with binary mixtures.

The temperature dependency of the adsorption constants is calculated with the Van't Hoff equation

$$
\ln K_{\mathrm{T}_{2}}=\frac{\Delta H_{A d}^{\circ}}{R} \cdot\left(\frac{1}{T_{1}}-\frac{1}{T_{2}}\right)+\ln K_{\mathrm{T}_{1}}
$$

Combining the adsorption model (Equation 6) with the kinetic model given in Equation 9 results in the overall kinetic model presented in Equation 10. $k_{\mathrm{f}}$ and $k_{\mathrm{r}}$ represent the rate constants for the forward and the reverse reaction, respectively.

$$
\frac{\mathrm{d} x_{\mathrm{i}}}{\mathrm{d} t}=\frac{v_{\mathrm{i}} m_{\mathrm{cat}}}{n_{0}} k_{\mathrm{f}} x_{\mathrm{MeOH}}^{\mathrm{S}} x_{\mathrm{HOAc}}^{\mathrm{S}}-k_{\mathrm{r}} x_{\mathrm{MeOAc}}^{\mathrm{S}} x_{\mathrm{H}_{2} \mathrm{O}}^{\mathrm{S}}
$$

$$
\frac{\mathrm{d} x_{i}}{\mathrm{~d} t}=\frac{v_{i} m_{\mathrm{cat}}}{n_{0}} \frac{k_{\mathrm{f}} K_{\mathrm{MeOH}} K_{\mathrm{HOAc}} a_{\mathrm{MeOH}} a_{\mathrm{HOAc}}-k_{\mathrm{r}} K_{\mathrm{MeOAc}} K_{\mathrm{H}_{2} \mathrm{O}} a_{\mathrm{MeOAc}} a_{\mathrm{H}_{2} \mathrm{O}}}{\left(1+a_{\mathrm{MeOH}} K_{\mathrm{MeOH}}+a_{\mathrm{HOAc}} K_{\mathrm{HOAc}}+a_{\mathrm{MeOAc}} K_{\mathrm{MeOAc}}+a_{\mathrm{H}_{2} \mathrm{O}} K_{\mathrm{H}_{2} \mathrm{O}}\right)^{2}}
$$


For modelling, the mole fractions of the reactants were derived through numerical simulation (Runge-Kutta fourth-order) using Equation 10. $x_{\mathrm{i}}$ represents the total mole fraction of component $i$. The resulting mole fractions in the liquid phase $x_{\mathrm{i}, \mathrm{l}}$ were derived through the overall material balance. When instantaneous equilibration in the adsorption step is assumed, the overall balance is in accordance with Equation 11

$$
\begin{gathered}
n_{\mathrm{i}, 0}=n_{\mathrm{i}}^{\mathrm{S}}+n_{\mathrm{i}, 1}=n^{\mathrm{S}} m_{\text {cat }} \frac{a_{\mathrm{i}} K_{\mathrm{i}}}{1+\sum a_{\mathrm{i}} K_{\mathrm{i}}}+ \\
+\left(n_{0}-n_{\mathrm{s}} m_{\text {cat }} \frac{\sum a_{\mathrm{i}} K_{\mathrm{i}}}{1+\sum a_{i} K_{\mathrm{i}}}\right) x_{\mathrm{i}, 1}
\end{gathered}
$$

from which the mole fraction of each reactant $x_{\mathrm{i}, 1}$ in the liquid phase can be determined. The rate constants for the forward and the reverse reaction $k_{\mathrm{f}}$ and $k_{\mathrm{r}}$ were then adapted using the least-squares method with respect to calculated and experimental liquid mole fractions. Methyl acetate was used as the key reactant for modelling.

\section{Results and discussion}

\section{Adsorption equilibrium constants of the reactants}

The adsorption of the non-reactive binary mixtures $\mathrm{MeOH}-\mathrm{H}_{2} \mathrm{O}$, $\mathrm{HOAc}-\mathrm{H}_{2} \mathrm{O}$, and $\mathrm{MeOAc}-\mathrm{MeOH}$ on Amberlyst ${ }^{\mathbb{}} 15$ was modelled with the multi-component Langmuir approach.

Figure $1\left(\mathrm{MeOH}-\mathrm{H}_{2} \mathrm{O}\right)$, Figure $2\left(\mathrm{HOAc}-\mathrm{H}_{2} \mathrm{O}\right)$, and Figure $3(\mathrm{MeOAc}-\mathrm{MeOH})$ present the relative adsorption behaviour of the binary mixtures at 313 K. Qualitatively, the experimentally obtained data compare well with the Langmuir isotherms, although deviation of fit data from experiments underline the disadvantages of this model (due to assumption of physical monolayer adsorption).

The adsorption affinity onto Amberlyst ${ }^{\circledR} 15$ increases with increasing polarity of the components. In the methyl acetate synthesis, water and methanol show the highest polarity and preferentially adsorb on the resin. Water, as the component with the highest polarity, shows the highest adsorption affinity. The amount of methanol adsorbed on Amberlyst ${ }^{\mathbb{B}} 15$ is, compared to water, less due to lower polarity.

As depicted from Figure 1 and Figure 2, the relative adsorption of water from $\mathrm{HOAc}-\mathrm{H}_{2} \mathrm{O}$ mixtures is higher than the relative water adsorption from mixtures of $\mathrm{MeOH}-\mathrm{H}_{2} \mathrm{O}$. Adsorption behaviour of the two polar components water and methanol is similar.

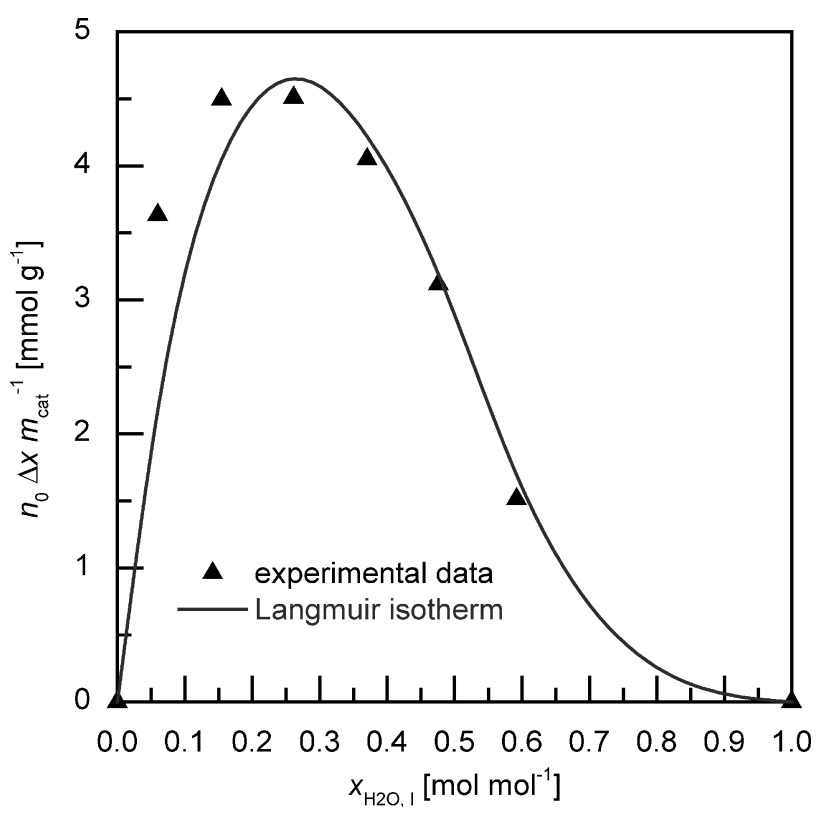

Fig. 1 - Relative adsorption of water from a binary $\mathrm{MeOH}-\mathrm{H}_{2} \mathrm{O}$ mixture on Amberlyst ${ }^{\circledR} 15$ at $313 \mathrm{~K}$

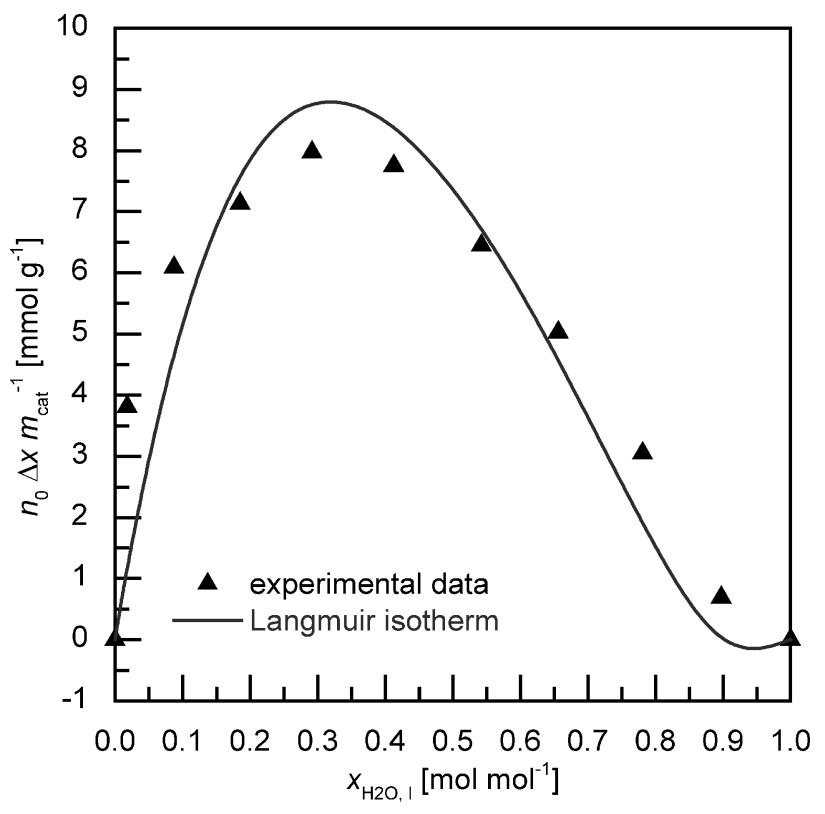

F ig. 2 - Relative adsorption of water from a binary $\mathrm{HOAc}-\mathrm{H}_{2} \mathrm{O}$ mixture on Amberlyst ${ }^{\circledR} 15$ at $313 \mathrm{~K}$

The adsorption equilibrium constants were derived through simultaneous modelling of all three binary data sets. According to the model, the maximum loading capacity of the ion-exchange resin was kept constant for all binary mixtures. The experimentally determined adsorption constants at $313 \mathrm{~K}$ are listed in Table 2 . The maximum loading capacity $n^{\mathrm{S}}$ was determined as $40.1 \mathrm{mmol} \mathrm{g}^{-1} \mathrm{Am}$ berlyst ${ }^{\circledR} 15$. Swelling of the ion-exchange resin in multi-component mixtures ${ }^{9}$ seemingly contributes to adsorption. 


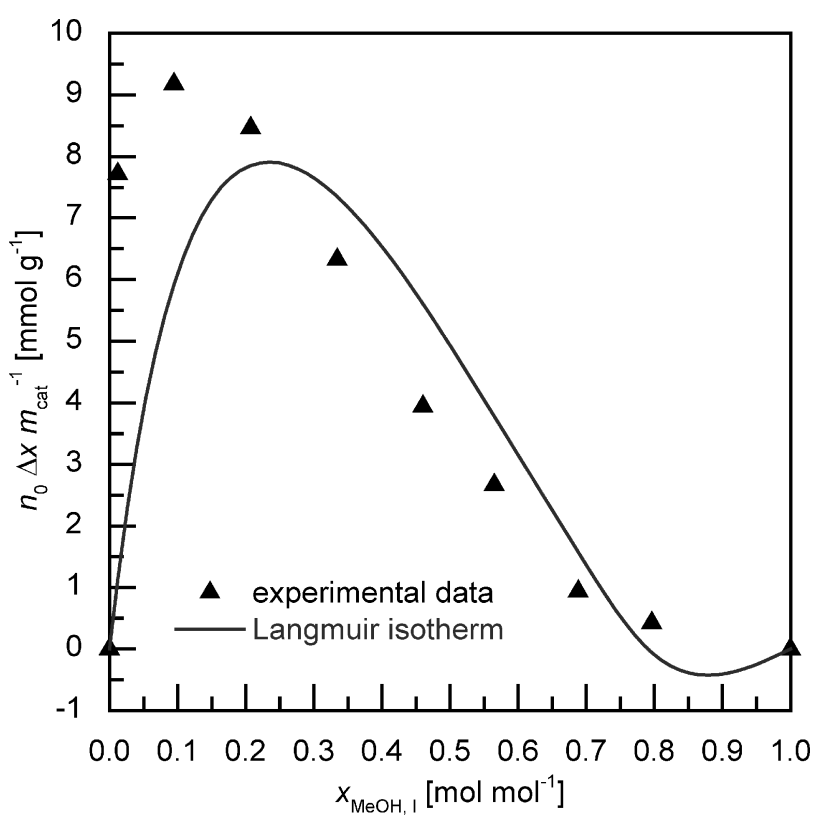

Fig. 3 - Relative adsorption of methanol from a binary MeOAc-MeOH mixture on Amberlyst ${ }^{\circledR} 15$ at $313 \mathrm{~K}$

Table 2 - Adsorption equilibrium constants for water, methanol, acetic acid, and methyl acetate on Amberlyst ${ }^{\circledR} 15$ at $313 \mathrm{~K}$

\begin{tabular}{c|c|c|c}
\hline$K_{\mathrm{H}_{2} \mathrm{O}}$ & $K_{\mathrm{MeOH}}$ & $K_{\mathrm{HOAc}}$ & $K_{\mathrm{MeOAc}}$ \\
\hline 4.76 & 3.60 & 2.19 & 1.96 \\
\hline
\end{tabular}

As expected, the adsorption equilibrium constants decrease in the order $\mathrm{H}_{2} \mathrm{O}>$ methanol $>$ acetic acid $>$ methyl acetate according to their decreasing polarity. The adsorption equilibrium constant of methyl acetate (1.96) is lower than the adsorption equilibrium constant of acetic acid (2.19). This results from the electron pushing effect of the second methylene group of the ester.

Determination of adsorption enthalpies was assumed crucial for the role of adsorption of constituents on Amberlyst ${ }^{\circledR} 15$. These investigations enable the evaluation of the temperature dependency of the adsorption equilibrium constants. Based on the adsorbed amount of constituent derived from Langmuir isotherms, the specific adsorption enthalpy was calculated. The results are given in Table 3.

The adsorption enthalpies are in the range of $-4.78 \mathrm{~kJ} \mathrm{~mol}^{-1}$ to $-1.85 \mathrm{~kJ} \mathrm{~mol}^{-1}$, indicating that the components are adsorbed physically on the surface of the ion-exchange resin. The trend of adsorption enthalpies compares well with the adsorption constants. $\mathrm{H}_{2} \mathrm{O}$, the most polar component in the reaction mixture, has the highest exothermic adsorption enthalpy. The adsorption enthalpies of the non-polar components methyl acetate and acetic acid have the smallest exothermic adsorption enthalpies. $\mathrm{H}_{2} \mathrm{O}$ also has the highest temperature dependence of the in-
Table 3 -Adsorbed amount $n_{i}^{S}$, heat of adsorption and adsorption enthalpy of the pure components acetic acid, methanol, methyl acetate, and water on the ion-exchange resin Amberlyst ${ }^{\circledR} 15$

\begin{tabular}{lccccc}
\hline & $\mathrm{H}_{2} \mathrm{O}$ & $\mathrm{MeOH}$ & $\mathrm{MeOAc}$ & $\mathrm{HOAc}$ \\
\hline $\begin{array}{l}\text { adsorbed amount } n_{\mathrm{i}}^{\mathrm{s}} \\
{\left[\mathrm{mmol} \mathrm{g}^{-1}\right]}\end{array}$ & 33.1 & 31.4 & 26.6 & 27.5 \\
$\begin{array}{l}\text { heat capacity } c_{\mathrm{pi}} \\
{\left[\mathrm{kJ} \mathrm{kg}^{-1} \mathrm{~K}^{-1}\right]}\end{array}$ & 4.19 & 1.89 & 2.5 & 2.05 \\
$\begin{array}{l}\text { heat of adsorption } Q_{\text {ads }} \\
{[\mathrm{kJ}]}\end{array}$ & 12.67 & 6.94 & 4.11 & 4.07 \\
$\begin{array}{l}\text { adsorption enthalpy } \Delta H_{\text {ads }} \\
{\left[\mathrm{kJ} \mathrm{mol}^{-1}\right]}\end{array}$ & -4.78 & -2.77 & -1.94 & -1.85 \\
\hline
\end{tabular}

vestigated components. With an increase in temperature, the amount of adsorbed components decreases (Table 4).

Table 4 -Adsorption equilibrium constants of water, methanol, acetic acid, and methyl acetate on Amberlyst ${ }^{\circledR} 15$ at temperatures between 303 and $333 \mathrm{~K}$

\begin{tabular}{c|c|c|c|c}
\hline$T[\mathrm{~K}]$ & $K_{\mathrm{H}_{2} \mathrm{O}}$ & $K_{\mathrm{MeOH}}$ & $K_{\mathrm{HOAc}}$ & $K_{\mathrm{MeOAc}}$ \\
\hline 303 & 5.06 & 3.73 & 2.24 & 2.01 \\
313 & 4.76 & 3.60 & 2.19 & 1.96 \\
323 & 4.50 & 3.48 & 2.14 & 1.92 \\
333 & 4.26 & 3.38 & 2.10 & 1.88 \\
\hline
\end{tabular}

Even though the temperature dependency of the adsorption is of minor relevance, it is employed into the kinetic model.

Pöpken et al. ${ }^{9}$ conducted swelling ratio experiments, which led them to the assumption of constant adsorbed mass on the ion-exchange resin. When calculating the specific adsorption enthalpy of each component based on the adsorbed amounts gained by their swelling ratio measurements, inconsistencies occur. The specific adsorption enthalpy of methyl acetate is greater than that of the polar component $\mathrm{H}_{2} \mathrm{O}$. These results could not be confirmed experimentally. Therefore, the assumption of constant adsorbed mass may not be suitable. Thus, assumption of constant total amount of adsorbed molecules may rather comply with experimental results.

\section{Reaction kinetics}

The investigation of reaction kinetics was conducted by altering the reaction conditions: agitation speed, amount of catalyst, temperature, particle size of the catalyst, and initial molar ratio of the reactants. The effect of the agitation speed was determined in the range of 40 to $150 \mathrm{rpm}$. It turned out that an enhancement of the mass transport had no impact on the rate of reaction. Therefore, an agita- 
tion speed of $50 \mathrm{rpm}$ was chosen to exclude limitations in the mass transport and minimize the abrasion of the catalyst.

The specific surface area of the ion-exchange resin was $53 \mathrm{~m}^{2} \mathrm{~g}^{-1}$. Experiments performed with samples of various distinct particle sizes $(250-500 \mu \mathrm{m}$, $500-800 \mu \mathrm{m},>800 \mu \mathrm{m})$ showed no impact on the rate of reaction. Hence, the internal mass transfer resistance of the porous catalyst particles is negligible in the investigated temperature range.

Preliminary investigations supported the assumption of the LHHW model, which states that the surface reaction is the rate-limiting step.

Figures 4 and 5 show the impact of the mass of catalyst on product formation. The solid lines represent the results of the Langmuir-Hinshelwood-Hougen-Watson model.

The model is in good agreement with the experimental values. The values for the rate constants of the forward and the reverse reaction are shown in Equations 12 and 13:

$$
\begin{gathered}
k_{\mathrm{f}}=7.77 \cdot 10^{7} \frac{\mathrm{mol}}{\mathrm{ming}} \mathrm{e}^{\frac{-55.4 \frac{\mathrm{kJ}}{\mathrm{mol}}}{R \cdot T}} \\
k_{\mathrm{r}}=4.02 \cdot 10^{6} \frac{\mathrm{mol}}{\mathrm{ming}} \mathrm{e}^{\frac{-58.0 \frac{\mathrm{kJ}}{\mathrm{mol}}}{R \cdot T}}
\end{gathered}
$$

The rate of reaction as well as the equilibrium mole fraction of methyl acetate rise with an increase in the amount of catalyst. Preferred adsorption of water is the reason for different mole fractions of methyl acetate at equilibrium. As shown in Table 4, $\mathrm{H}_{2} \mathrm{O}$ has the highest adsorption equilibrium constant. Due to its polarity, it preferably adsorbs on the surface of the catalyst. The concentration of $\mathrm{H}_{2} \mathrm{O}$ in the liquid phase simultaneously decreases. Polarity of methyl acetate is not that pronounced. Its affinity to adsorb on the catalyst is the smallest of all the constituents in the reaction mixture. The amount of adsorbed methyl acetate may be neglected. Figure 5 indicates an increased loading of the catalyst with $\mathrm{H}_{2} \mathrm{O}$. The occupation of active sites by $\mathrm{H}_{2} \mathrm{O}$ has a retarding effect on the rate of the esterification reaction. An increase of the catalyst amount results in a higher conversion, due to the greater amount of active sites. More $\mathrm{H}_{2} \mathrm{O}$ is formed until the catalyst is saturated, and reaction equilibrium as well as adsorption equilibrium is obtained.

All further experiments were conducted with constant catalyst mass of $30 \mathrm{~g}$. The effect of the reaction temperature on the mole fraction of methyl acetate and $\mathrm{H}_{2} \mathrm{O}$ is shown in Figures 6 and 7, respectively. The modelled values for the mole fractions of methyl acetate over the reaction time are in good agreement with the experimental results.

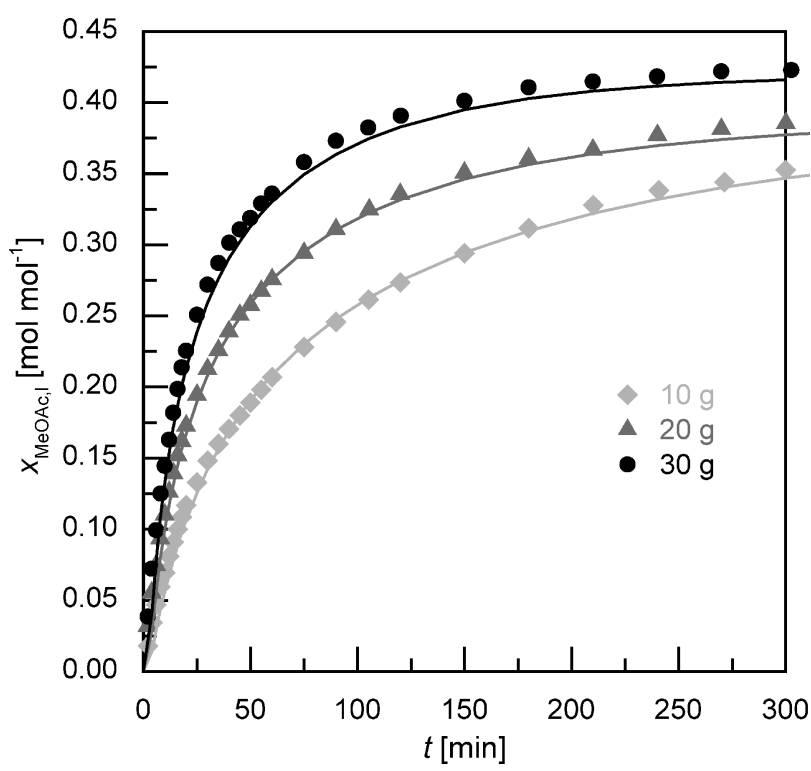

Fig. 4 - Mole fraction of methyl acetate in the liquid phase for varying amounts of catalyst (Amberlyst $\left.{ }^{\circledR} 15\right)$ at $313 \mathrm{~K}$, $m_{c a t}=10-30 \mathrm{~g}=7.2-21.6 \mathrm{mmol} \mathrm{H} / \mathrm{mol}$ of initial reaction mixture; experimental data are represented by data points, the kinetic model is shown by continuous lines

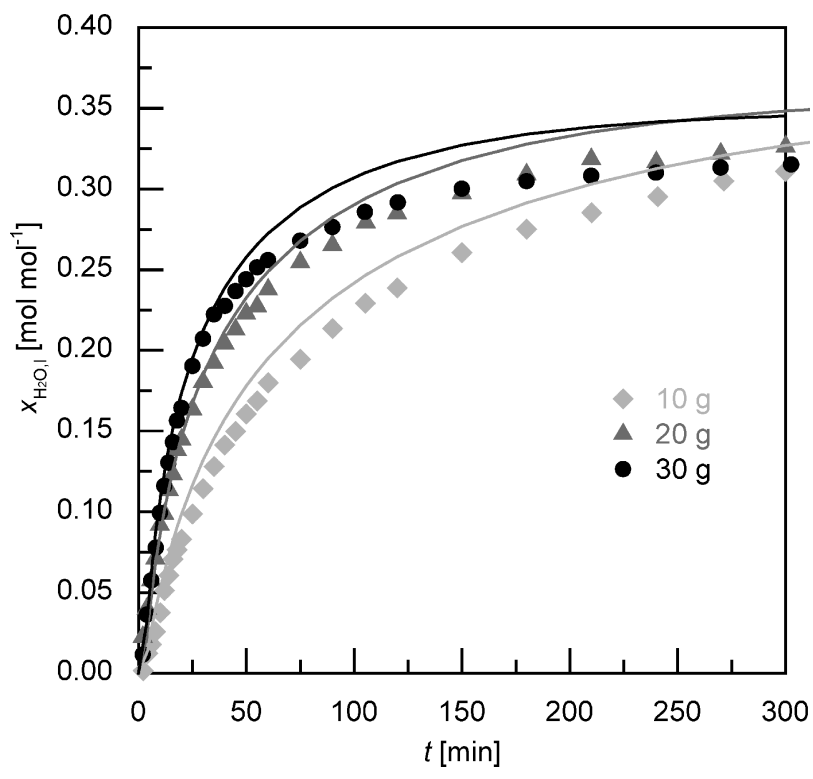

Fig. 5 - Mole fraction of $\mathrm{H}_{2} \mathrm{O}$ in the liquid phase for varying amounts of catalyst (Amberlyst $\left.{ }^{\circledR} 15\right)$ at $313 \mathrm{~K}, \mathrm{~m}_{\text {cat }}=10-30 \mathrm{~g}=$ 7.2-21.6 $\mathrm{mmol} \mathrm{H}^{+} / \mathrm{mol}$ of initial reaction mixture; experimental data are represented by data points, the kinetic model is shown by continuous lines

According to Arrhenius' Law, increasing reaction temperature does accelerate reaction. At equilibrium, the mole fraction of methyl acetate does not differ significantly for different reaction temperatures. The chemical equilibrium is not affected significantly by a change in the reaction temperature in the investigated temperature range. According to Table 4, the water adsorption capacity of the catalyst will slightly drop with increasing tempera- 


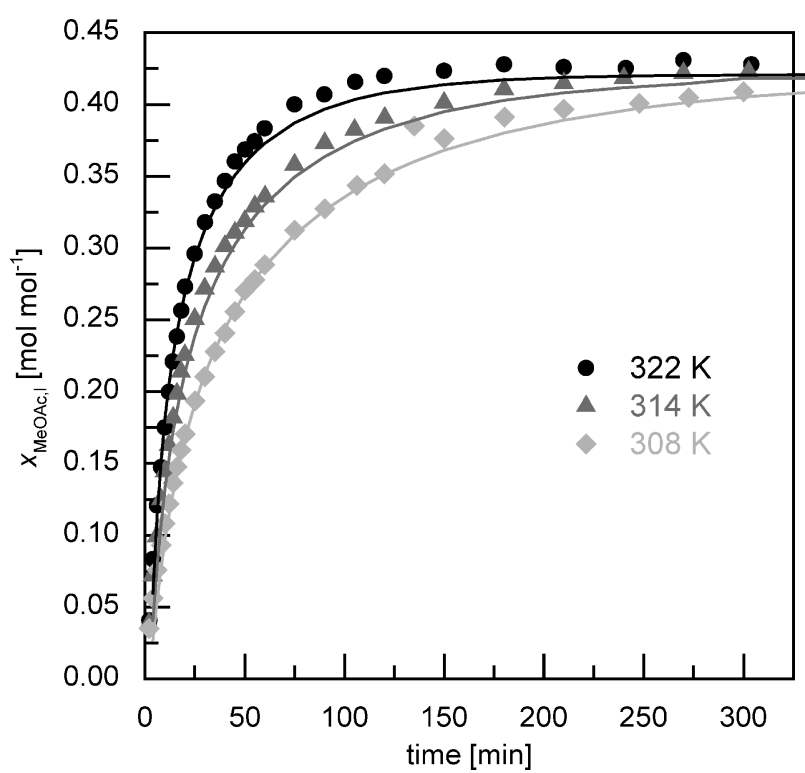

Fig. 6 - Liquid phase mole fractions of methyl acetate for varying temperatures, $T=308 / 314 / 323 K$, catalyst: Amberlyst $t^{\mathbb{R}} 15$, $m_{\text {cat }}=30 \mathrm{~g}=21.6 \mathrm{mmol} \mathrm{H}^{+} / \mathrm{mol}$ of initial reaction mixture; experimental data are represented by data points, the kinetic model is shown by continuous lines

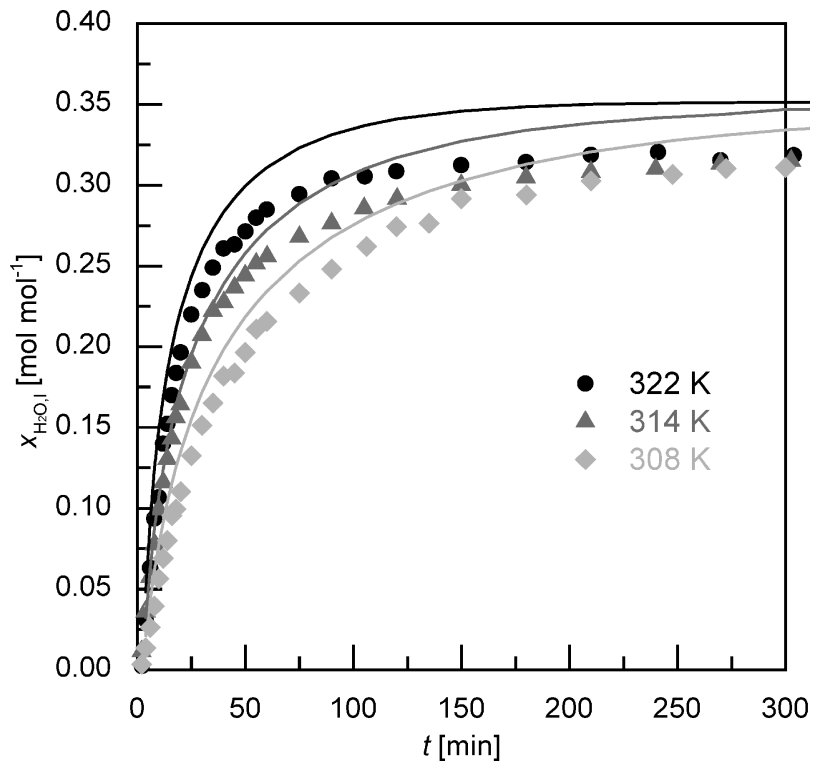

Fig. 7 - Liquid phase mole fractions of water for varying temperatures, $T=308 / 314 / 323 \mathrm{~K}$, catalyst: Amberlyst ${ }^{\mathbb{B}} 15$,

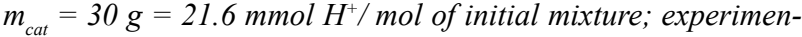
tal data are represented by data points, the kinetic model is shown by continuous lines

ture. The enthalpy of reaction calculated from standard enthalpy of formation is $\Delta_{\mathrm{R}} H^{\circ}=-8.2 \mathrm{~kJ} \mathrm{~mol}^{-1}$ at $T=298 \mathrm{~K}$, explaining the small impact of the reaction temperature on the equilibrium.

Figures 8 and 9 show the mole fractions of methyl acetate and $\mathrm{H}_{2} \mathrm{O}$ for varying initial molar ratio of methanol and acetic acid.

Equimolar amounts of acetic acid and methanol lead to a maximum concentration of methyl acetate

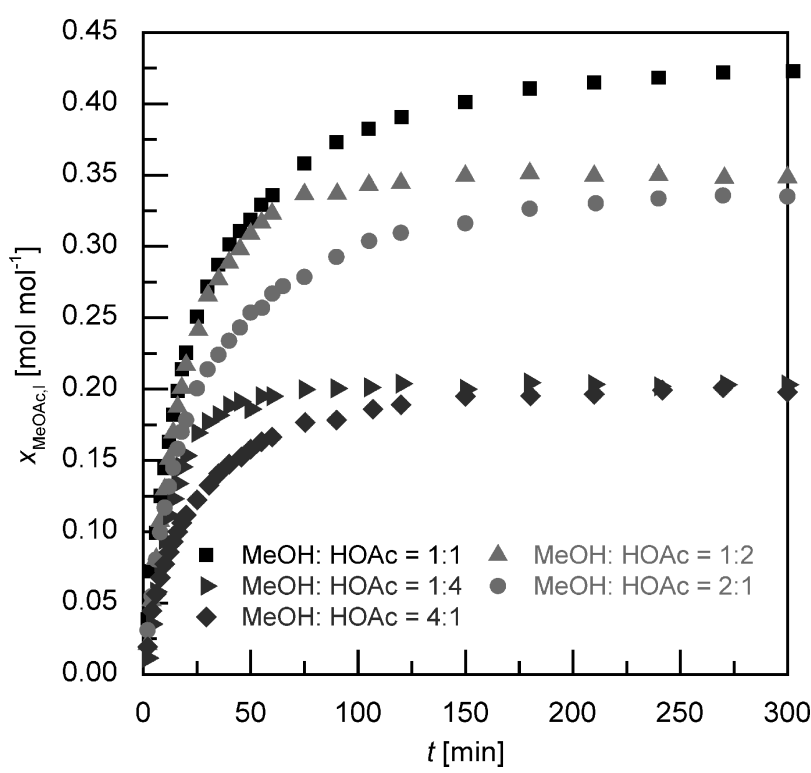

Fig. 8 - Mole fraction of methyl acetate in the liquid phase for varying initial molar ratios of methanol and acetic acid at $313 \mathrm{~K}$, catalyst: Amberlyst ${ }^{\mathbb{B}} 15, m_{\text {cat }}=30 \mathrm{~g}=21.6 \mathrm{mmol} \mathrm{H}^{+} / \mathrm{mol}$ of initial mixture

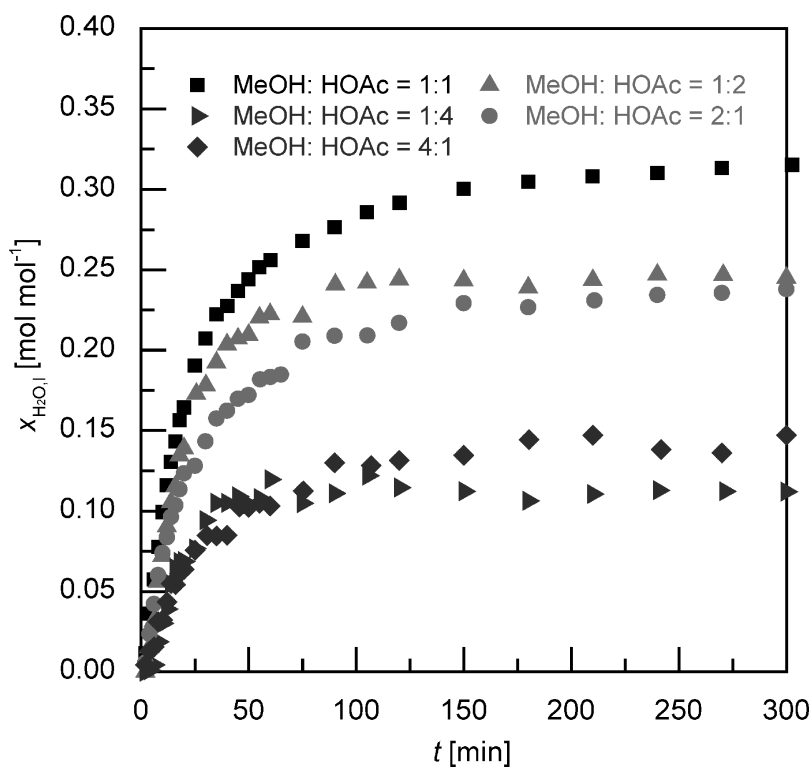

Fig. 9 - Mole fraction of $\mathrm{H}_{2} \mathrm{O}$ in the liquid phase for varying initial molar ratios of methanol and acetic acid at $313 \mathrm{~K}$, catalyst: Amberlyst $t^{\mathbb{B}} 15, m_{\text {cat }}=30 \mathrm{~g}=21.6 \mathrm{mmol} \mathrm{H}^{+} / \mathrm{mol}$ of initial mixture

at equilibrium. In experiments with acetic acid in excess, the rate of reaction is significantly higher compared with experiments when acetic acid is the limiting component. Again, the different adsorption behaviour of components explains the phenomenon, as shown in Table 4. The effect of the low adsorption equilibrium constant of acetic acid is compensated with acetic acid in excess. The rate of esterification reaction is enhanced. When methanol is added in excess, methanol adsorbs predominately and acetic acid will adsorb to a lesser amount. Con- 
sequently, the rate of reaction is limited by the limited adsorption of acetic acid. Mole fractions of $\mathrm{H}_{2} \mathrm{O}$ differ from mole fractions of methyl acetate because of the distinct difference in adsorption properties. For an initial molar ratio of methanol to acetic acid of 4:1, the mole fraction of $\mathrm{H}_{2} \mathrm{O}$ at chemical equilibrium is significantly higher compared to that with an initial molar ratio of methanol to acetic acid of 1:4, because excess methanol compensates for the better adsorption properties of water.

\section{Conclusions}

The heterogeneous catalytic esterification of acetic acid with methanol was modelled with the adsorption-based Langmuir-Hinshelwood-Hougen-Watson approach. Independent adsorption experiments were performed with the non-reactive binary mixtures $\mathrm{HOAc}-\mathrm{H}_{2} \mathrm{O}, \mathrm{MeOH}-\mathrm{H}_{2} \mathrm{O}$, and $\mathrm{MeOAc}-\mathrm{MeOH}$ to gain quantitative information about the role of adsorption of species on the rate of the chemical reaction. The enthalpy of adsorption of all reactants was determined in order to account for the type of interaction of constituents and catalyst. From the enthalpy of adsorption, which was below $-10 \mathrm{~kJ} \mathrm{~mol}^{-1}$ for all constituents, physical interaction of constituents and catalyst was concluded. The Langmuir-Hinshelwood-Hougen-Watson model showed good agreement with the experimental results.

\section{ACKNOWLEDGEMENTS}

The authors gratefully acknowledge the support from NAWI Graz.

\section{References}

1. Riemenschneider, W., Bolt, H. M., Esters, Organic, in Ullmann's Encyclopedia of Industrial Chemistry, Wiley-VCH Verlag GmbH \& Co. KGaA, Weinheim, 2005. doi: http://dx.doi.org/10.1002/14356007.a09_565.pub2

2. Yu, W., Hidajat, K., Ray, A. K., Determination of adsorption and kinetic parameters for methyl acetate esterification and hydrolysis reaction catalyzed by Amberlyst 15, Appl. Catal. A 260 (2004) 191.

doi: http://dx.doi.org/10.1016/j.apcata.2003.10.017
3. Neumann, R., Sasson, Y., Recovery of dilute acetic acid by esterification in a packed chemorectification column, Ind. Eng. Chem. Process Des. Dev. 23 (1984) 654 doi: http://dx.doi.org/10.1021/i200027a005

4. Xu, Z. P., Chuang, K. T., Kinetics of acetic acid esterification over ion exchange catalysts, Can. J. Chem. Eng. 74 (1996) 493. doi: http://dx.doi.org/10.1002/cjce.5450740409

5. Cheung, H., Tanke, R. S., Torrence, G. P., Acetic Acid, in Ullmann's Encyclopedia of Industrial Chemistry, Wiley-VCH Verlag GmbH \& Co. KGaA, Weinheim, 2011. doi: http://dx.doi.org/10.1002/14356007.a01_045.pub2

6. Rönnback, R., Salmi, T., Vuori, A., Haario, H., Lehtonen, J., Sundqvist, A., Development of a kinetic model for the esterification of acetic acid with methanol in the presence of a homogeneous acid catalyst, Chem. Eng. Sci. 52 (1997) 3369. doi: http://dx.doi.org/10.1016/S0009-2509(97)00139-5

7. Gmehling, J., Onken, U., Rarey-Nies, J. R., DECHEMA Chemistry Data Series, Vapor-Liquid Equilibrium Data Collection. Vol.1, Part 1b: Aqueous Systems (Supplement 2), 1988.

8. Gmehling, J., Onken, U., Arlt, W., DECHEMA Chemistry Data Series, Vapor-Liquid Equilibrium Data Collection. Vol. 1, Part 2c: Organic Hydroxy Compounds: Alcohols (Supplement 1), 1982.

9. Pöpken, T., Götze, L., Gmehling, J., Reaction Kinetics and Chemical Equilibrium of Homogeneously and Heterogeneously Catalyzed Acetic Acid Esterification with Methanol and Methyl Acetate Hydrolysis, Ind. Eng. Chem. Res. 39 (2000) 2601 doi: http://dx.doi.org/10.1021/ie000063q

10. Song, W., Venimadhavan, G., Manning, J. M., Malone, M. F., Doherty, M. F., Measurement of Residue Curve Maps and Heterogeneous Kinetics in Methyl Acetate Synthesis, Ind. Eng. Chem. Res. 37 (1998) 1917. doi: http://dx.doi.org/10.1021/ie9708790

11. Tsai, Y.-T., Lin, H.-M., Lee, M.-J., Kinetics behavior of esterification of acetic acid with methanol over Amberlyst 36, Chemical Engineering Journal 171 (2011) 1367. doi: http://dx.doi.org/10.1016/j.cej.2011.05.049

12. Gausepohl, H., Gellert, R., Polystyrol, Kunststoff-Handbuch, C. Hanser Verlag, München, 1996.

13. Kipling, J. J., Adsorption from Solutions of Non-Electrolytes, Academic Press, New York, 1965.

14. Roque-Malherbe, R. M. B., Adsorption and Diffusion in Nanoporous Materials, CRC Press, 2007. doi: http://dx.doi.org/10.1201/9781420046762

15. Markham, E. C., Benton, A. F., The Adsorption of Gas Mixtures by Silica, J. Am. Chem. Soc. 53 (1931) 497. doi: http://dx.doi.org/10.1021/ja01353a013

16. Gmehling, J., Onken, U., Grenzheuser, P., DECHEMA Chemistry Data Series, Vapor-Liquid Equilibrium Data Collection. Vol. 1, Part 5: Carboxylic Acids, Anhydrides, Esters, 1982. 